\title{
Coverage of private sector community midwife services in rural Punjab, Pakistan: development and demand
}

\author{
Zubia Mumtaz ${ }^{1 *}$, Adrienne V. Levay ${ }^{1}$, Gian S. Jhangri ${ }^{1}$ and Afshan Bhatti ${ }^{2}$
}

\begin{abstract}
Background: In 2007, the Government of Pakistan introduced a new cadre of community midwives (CMWs) to address low skilled birth attendance rates in rural areas; this workforce is located in the private-sector. There are concerns about the effectiveness of the programme for increasing skilled birth attendance as previous experience from private-sector programmes has been sub-optimal. Indonesia first promoted private sector midwifery care, but the initiative failed to provide universal coverage and reduce maternal mortality rates.

Methods: A clustered, stratified survey was conducted in the districts of Jhelum and Layyah, Punjab. A total of 1,457 women who gave birth in the 2 years prior to the survey were interviewed. $x^{2}$ analyses were performed to assess variation in coverage of maternal health services between the two districts. Logistic regression models were developed to explore whether differentials in coverage between the two districts could be explained by differential levels of development and demand for skilled birth attendance. Mean cost of childbirth care by type of provider was also calculated.

Results: Overall, $7.9 \%$ of women surveyed reported a CMW-attended birth. Women in thelum were six times more likely to report a CMW-attended birth than women in Layyah. The mean cost of a CMW-attended birth compared favourably with a dai-attended birth. The CMWs were, however, having difficulty garnering community trust. The majority of women, when asked why they had not sought care from their neighbourhood CMW, cited a lack of trust in CMWs' competency and that they wanted a different provider.

Conclusions: The CMWs have yet to emerge as a significant maternity care provider in rural Punjab. Levels of overall community development determined uptake and hence coverage of CMW care. The CMWs were able to insert themselves into the maternal health marketplace in Jhelum because of an existing demand. A lower demand in Layyah meant there was less 'space' for the CMWs to enter the market. To ensure universal coverage, there is a need to revisit the strategy of introducing a new midwifery workforce in the private sector in contexts of low demand and marketing the benefits of skilled birth attendance.
\end{abstract}

Keywords: Cost of care, Coverage, Private sector, Skilled birth attendant, Social determinants

\footnotetext{
* Correspondence: zubia.mumtaz@ualberta.ca

'School of Public Health, University of Alberta, 3-309 Edmonton Clinic Health

Academy, 1140 - 87 Ave, Edmonton, AB T6G 1C9, Canada

Full list of author information is available at the end of the article
} 


\section{Background}

Pakistan, with a maternal mortality rate (MMR) of 260 deaths per 100,000 live births [1], is one of six countries contributing to half of all maternal deaths worldwide [2]. A large body of historic and contemporary evidence from around the world has shown the introduction of an effective midwifery workforce is one of the most important elements of any maternal mortality reduction strategy.

Drawing on this well-acknowledged evidence, the Government of Pakistan introduced a new cadre of skilled birth attendants, the Community Midwives (CMWs) [3]. With the objective of providing skilled birth attendance to women living in rural areas, a large majority of whom prefer to give birth at home, the programme aimed to deploy 12,000 CMWs over a 5 year period between 2007 and 2012 [3]. Young, rural women who met recruitment criteria were given 18 months of midwifery training and were then deployed back to their home villages and expected to establish a private midwifery practice that provided care to a population of approximately 10,000. The CMWs were to establish home-based clinics and provide domiciliary antenatal care (ANC), childbirth, and postnatal care to rural women, as well as divert those currently using traditional birth attendants, or dais, to their skilled care. They were supported with a small stipend for the first 2 years after their training while establishing their practices. To date, over 8,000 CMWs have been deployed [3].

Concerns about the effectiveness of the programme for increasing coverage of skilled birth attendance in rural areas remain, particularly as the CMWs are located in the private sector. Historically successful midwifery programmes, such as ones from Sweden, England, Sri Lanka, and Thailand, have largely situated midwives in the public sector. The concept of locating a midwifery workforce in the private sector was first introduced by Indonesia in the 1980s; between 1989 and 1996, Indonesia deployed 54,000 midwives in as many villages in the country [4]. The trained midwives were provided with a government contract for 3 years and encouraged to develop a private practice with the expectation that they would gradually shift to a full private practice after 3-6 years [4]. Nearly 30 years later, the Indonesian MMR has stagnated at a high of 220/ 100,000 live births after an initial optimistic decline [5]. This stagnation is worrisome because MMR is one of the few health indicators that can be rapidly and consistently decreased. Malaysia and Sri Lanka halved their MMRs every 6-12 years between the 1950s and 1990s [6].

A large body of literature suggests that the Indonesian programme faltered because the midwives could not sustain their private practices after the expiration of their government contract [7-9]. Those who did manage to establish financially sustainable practices did so by serving wealthier clients, effectively excluding those who could not afford to pay their fees. According to the 2007 Indonesian Demographic Health Survey [10], 59\% of poor women were still being attended by traditional birth attendants, while $80 \%$ of wealthy women were attended by nurses/midwives. This suggests the private sector model of midwifery care, with its inherent dependence on fee-paying clients, fails to provide universal coverage that is essential for the eradication of avoidable maternal deaths.

The design of the Pakistani CMW programme is similar to the Indonesian midwifery initiative. Like the Indonesian programme, the Pakistani CMWs are located in the private sector [3]. Further, recent evidence suggests that the Pakistani CMWs are also facing the same challenge in establishing private practices [11-13], given that young, under-confident women are perceived to have questionable competencies [12-14], resulting in a lack of trust from community women and their families $[12,13]$. Furthermore, young women cannot travel unhindered, a consequence of gendered norms that promote women's seclusion in this context $[11,13]$; this limits the young CMWs' ability to advertise their services and provide domiciliary care. Geographic distances, difficult terrain, and lack of transport infrastructure further exacerbate the CMWs' ability to access clients [11].

Given the similarity of the Pakistani and Indonesian programmes, the question arises whether, 4 years after launch, the Pakistani CMW programme is expanding coverage of skilled birth attendance. Are there variations in uptake by demand for skilled birth attendants, which are in turn determined by overall levels of population education and socioeconomic status? Are CMW fees a factor in uptake of their services?

The present paper will address these questions using data from the districts of Jhelum and Layyah in Punjab; Jhelum being a relatively well-developed district [15], and Layyah one of the least developed [16]. The findings from this research will provide programme policymakers and managers with empirical evidence of the potential role of private sector skilled birth attendant programmes in contexts characterized by low levels of development.

\section{Methods}

A cross-sectional, clustered, and stratified survey was conducted in two districts, Jhelum and Layyah, in the province of Punjab between November 2011 and July 2012. These districts were purposely selected because they were some of the first districts in which the programme was launched, they were safe enough for the researchers to collect data from, and span the range of socioeconomic development in Punjab. Historically, rain-fed agricultural practices in Jhelum could not sustain livelihoods, and men migrated to urban areas to find employment. This has led 
to overall higher levels of education and income levels in Jhelum. Layyah's agriculture is based on a stable aqueduct irrigation system. The majority of residents are refugees settled here after migration from India in 1947, as well as a result of other natural disasters. The refugees were given small pieces of land that, because of the aqueduct, were sufficient to support families. It was postulated that these two districts would provide insight into the potential range of CMW coverage in the province, while acknowledging that the rates may not be representative of Punjab.

The study population consisted of women aged 15-49, who had given birth in the 2 years prior to the survey, and lived in CMW-served catchment areas (study clusters). The 2 year limit was used because the first batch of CMWs graduated in 2008. A total of 1,457 women were surveyed, 747 in Jhelum and 710 in Layyah. This sample size was calculated using the Pakistan Demographic Health Survey 2007 data [16], which showed that the probability of skilled birth attendance ranges from 0.25 in the lower half of the socioeconomic index, to 0.5 in the upper half of the index. This translates into an odds ratio (OR) of 3.0. To be conservative, we chose an OR of 1.8. In order to detect this difference with $80 \%$ power and 0.05 significance level, based on a logistic regression model of a binary outcome variable (skilled attendance at birth) on a binary independent variable (socioeconomic index), we estimated a minimum sample size of 880 women. This sample size was increased to 1,450 to take into account a multiple correlation between socioeconomic index and other predictor variables of 0.6 and a design factor of 1.3.

The sampling frame was drawn up using a three-stage stratified sample design. In the first stage, three out of four tehsils (sub-district units) in district Jhelum were randomly selected. All three tehsils in Layyah were selected. In the second stage, five union councils were randomly selected from each tehsil for a total of 30 union councils. If there was no CMW in a selected union council as indicated by programme records, it was replaced. In the third stage, two villages were randomly selected from each union council. However, if there were not enough eligible women in the selected village, a neighbouring village was included. This led to a total of 48 villages surveyed in Layyah and 69 villages in Jhelum. Within each selected village, a maximum of 22 women who gave birth in the 2 years prior to the survey were interviewed [17]. Given that about a quarter of the South Asian population is classified as low-caste and tend to be invisible, this group was oversampled $[18,19]$. We ensured that at least 11 of the 22 women interviewed in each village were landless and belonged to lower status castes. Lady health workers (LHWs) maintain records of births, deaths, and health status of all the members of households in their catchment populations. The women were surveyed in person by female enumerators. Using a pre-tested questionnaire, sociodemographic data, whether they sought ANC and from whom, place of delivery, type of birth attendant, and the amount spent on childbirth were explored.

Data were analyzed using Stata 11.0 [20]. Since lowcaste women were oversampled, data was weighted on the basis that $25 \%$ of the population in South Asia is categorised as low-caste. All data was analyzed using 'svy' Stata commands to take into account both the weighting and stratified nature of the data. $x^{2}$ analyses were done to assess the sociodemographic characteristics of the sample population, use of ANC, type of ANC provider, type of birth attendant, and place of delivery stratified by district. Means were calculated for continuous data such as age, number of children, and cost of childbirth care. Logistic regression models using the forward selection approach were developed to find out if differentials in coverage between the two districts could be explained by differential levels of development and demand for skilled birth attendance.

Ethics approval was obtained from the University of Alberta Health Research Ethics Board and the National Bioethics Committee, Pakistan.

\section{Results}

The mean age of our sample of 1,457 rural Punjabi women in Jhelum and Layyah was 28 years; $38 \%$ had received no schooling, almost all were currently married, with an average of 2.9 children. Overall, women in district Jhelum had higher levels of education, with twice as many women having 10 years of schooling compared to Layyah ( $37 \%$ vs. $19 \%)$. Women in Jhelum were wealthier, with only $18 \%$ classified as poor, compared to $33 \%$ in Layyah. Table 1 provides the sociodemographic characteristics of these women by district.

\section{Use of CMW services}

Overall, $47 \%$ of respondents knew of the presence of a CMW in their area, $62 \%$ in Jhelum and $38 \%$ in Layyah $(P<0.001)$. Of these $47 \%$, the majority knew that the CMW provided childbirth services and nearly $80 \%$ had had contact with her in the context of an introductory home-visit or provision of antenatal, postnatal, and general medical care(Table 2).

CMWs have yet to emerge as a significant provider of maternal health services. Only $8.3 \%$ of women reported having received ANC from a CMW. This proportion is small given that uptake of at least one ANC visit is almost universal. Similarly, CMWs attended only $7.9 \%$ of all births. There were, however, noticeable differences by district. Nearly $14 \%$ of women in Jhelum reported receiving ANC from a CMW and $12.4 \%$ reported CMW-attended births. In Layyah, only $2.4 \%$ of women 
Table 1 Sociodemographic characteristics of women included, overall and by district

\begin{tabular}{|c|c|c|c|c|}
\hline \multirow[t]{2}{*}{ Sociodemographic indicator } & \multirow{2}{*}{$\begin{array}{l}\text { Overall } \\
(n=1457)\end{array}$} & \multicolumn{2}{|l|}{ District } & \multirow[t]{2}{*}{$P$ value } \\
\hline & & Jhelum $(n=747)$ & Layyah $(n=710)$ & \\
\hline Age, mean $\pm S D$ & $28.3 \pm 0.15$ & $28.0 \pm 0.21$ & $28.5 \pm 0.22$ & 0.99 \\
\hline Currently married, \% & 99.3 & 99.2 & 99.3 & 0.20 \\
\hline Mean number of children, mean \pm SD & $2.9 \pm 0.05$ & $2.7 \pm 0.07$ & $3.1 \pm 0.08$ & 1.00 \\
\hline Caste, \% & & & & 0.00 \\
\hline High caste & 45.4 & 59.3 & 30.8 & \\
\hline Middling caste & 29.6 & 15.7 & 44.2 & \\
\hline Low caste (Kammis) & 25.0 & 25.0 & 25.0 & \\
\hline Education, \% & & & & 0.00 \\
\hline No education & 38.2 & 24.5 & 52.7 & \\
\hline $1-5$ years schooling & 26.9 & 30.0 & 23.7 & \\
\hline $6-10$ years schooling & 28.1 & 36.9 & 18.6 & \\
\hline More than 11 years schooling & 6.8 & 8.6 & 5.1 & \\
\hline Husband's education, \% & & & & 0.00 \\
\hline No education & 20.7 & 14.3 & 27.5 & \\
\hline $1-5$ years schooling & 14.9 & 11.2 & 18.7 & \\
\hline $6-10$ years schooling & 50.8 & 62.2 & 38.8 & \\
\hline More than 11 years schooling & 13.6 & 12.4 & 15.0 & \\
\hline \multicolumn{5}{|l|}{ Employment, \% } \\
\hline Yes & 11.5 & 3.1 & 20.4 & 0.00 \\
\hline If employed, type of work $(n=199), \%$ & & & & 0.00 \\
\hline Professional & 10.3 & 18.2 & 9.0 & \\
\hline Skilled workers & 67.0 & 68.2 & 66.9 & \\
\hline Agricultural labourers on other's land & 13.4 & 0 & 15.2 & \\
\hline Unskilled workers ${ }^{a}$ & 9.3 & 13.6 & 9.0 & \\
\hline Husband's occupation, \% & & & & 0.00 \\
\hline Professional/landowner & 16.4 & 9.6 & 23.6 & \\
\hline Skilled worker & 46.7 & 56.1 & 36.7 & \\
\hline Agricultural labourer on other's land & 5.4 & 0.9 & 10.0 & \\
\hline Unskilled worker & 29.3 & 29.5 & 29.3 & \\
\hline Not working/unemployed & 2.2 & 3.9 & 0.4 & \\
\hline Material asset index, $\%$ & & & & 0.00 \\
\hline First quartile (poorest) & 25.9 & 18.7 & 33.4 & \\
\hline Second quartile & 25.3 & 24.2 & 26.4 & \\
\hline Third quartile & 24.0 & 27.7 & 20.1 & \\
\hline Fourth quartile (wealthy) & 24.9 & 29.4 & 20.2 & \\
\hline
\end{tabular}

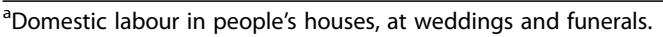

reported receiving $\mathrm{ANC}$ by a $\mathrm{CMW}$ and $3.2 \%$ reported a CMW-attended birth $(P<0.001)$ (Table 2$)$.

CMW home-clinics are a negligible child-birth facility with just $1 \%$ of all births occurring here. While reflective of the overall low levels of CMW care, the low rates also imply that the CMWs are providing domiciliary care; $77 \%$ of $\mathrm{CMW}$-attended births took place in women's own homes. Of the women who sought ANC from a CMW, 93\% reported being satisfied or very satisfied with CMW care (Table 2).

Multivariate logistic regression showed that women in district Jhelum were six times more likely to report a CMW-attended birth compared to women in Layyah. This relationship strengthened significantly after adjusting for women's age, education, their husband's education, their occupation, husband's occupation, and Material Asset 
Table 2 Women's use of CMW services by district (\%)

\begin{tabular}{|c|c|c|c|c|}
\hline \multirow[t]{2}{*}{ Maternal health service use indicator } & \multirow{2}{*}{$\begin{array}{l}\text { Overall } \\
(n=1457)\end{array}$} & \multicolumn{2}{|l|}{ District } & \multirow[t]{2}{*}{$P$ value } \\
\hline & & Jhelum $(n=747)$ & Layyah $(n=710)$ & \\
\hline Sought at least one antenatal care (ANC) visit & 96.6 & 97.8 & 95.3 & 0.01 \\
\hline \multicolumn{5}{|l|}{ Type of ANC provider } \\
\hline Community Midwife (CMW) & 8.3 & 13.8 & 2.4 & 0.00 \\
\hline Doctor & 57.5 & 57.2 & 57.8 & 0.83 \\
\hline Skilled birth attendant & 27.2 & 24.3 & 30.4 & 0.02 \\
\hline Dai & 4.6 & 2.6 & 6.7 & 0.00 \\
\hline \multicolumn{5}{|l|}{ Type of childbirth attendant } \\
\hline CMW & 7.9 & 12.4 & 3.2 & 0.00 \\
\hline Doctor & 36.1 & 47.6 & 24 & 0.00 \\
\hline Non-physician skilled birth attendant & 25.5 & 26.3 & 24.6 & 0.49 \\
\hline Dai/traditional birth attendant & 30.5 & 13.7 & 48.2 & 0.00 \\
\hline \multicolumn{5}{|l|}{ Place of delivery } \\
\hline Home (home and dai home) & 41.2 & 29.3 & 54 & 0.00 \\
\hline CMW clinic/home & 1.1 & 3.1 & 0.7 & 0.01 \\
\hline Government & 21.6 & 27.1 & 15.9 & 0.00 \\
\hline Private & 35.1 & 40.5 & 29.4 & 0.00 \\
\hline \multicolumn{5}{|l|}{ Satisfaction with CMW care } \\
\hline For ANC $(n=245)$ & & & & 0.05 \\
\hline Very satisfied & 39.5 & 44.2 & 12.9 & \\
\hline Satisfied & 53.7 & 50.0 & 74.2 & \\
\hline Somewhat satisfied & 2.9 & 1.8 & 9.6 & \\
\hline Somewhat dissatisfied/dissatisfied & 4.0 & 4.0 & 3.3 & \\
\hline For delivery (competency) $(n=109)$ & & & & 0.00 \\
\hline Very satisfied & 68.1 & 75.2 & 39.3 & \\
\hline Satisfied & 28.5 & 21.1 & 58.5 & \\
\hline Somewhat satisfied & 1.7 & 1.6 & 2.2 & \\
\hline Somewhat dissatisfied/dissatisfied & 1.7 & 2.2 & 0.0 & \\
\hline
\end{tabular}

Values are presented as \%.

Index. As seen in Table 3, none of these individual level sociodemographic characteristics had an independent relationship with a CMW-attended birth, but were included in the final model to control for important sociodemographic variables. The $P$ value for the goodness-of-fit of the model was 0.151 , indicating a good fit.

\section{Cost of CMW services}

A CMW-attended birth cost a mean of PKR 2950 (US \$28; Table 4). This average masked the vast range of reported fees, from PKR 500-25,000 (US \$5-240). The mean and the range are comparable with the cost of a dai-attended birth, which also ranged from PKR 20025,000 (US \$1.9-240). In contrast, a physician-attended birth cost, on average, PKR 13,000 (US \$125) and ranged from PKR 200-60,000 (US \$1.9-577). There was, however, a vast variation in physician-attended births in the public and private sectors, costing PKR 7,800 (US \$75) and PKR 15,670 (US \$151), respectively. Overall, 64\% of CMW clients had saved money for their childbirth.

\section{Reasons for not seeking CMW care}

Women who knew of a CMW and her services in their neighbourhoods, but had not sought care from the CMW, were asked their reasons for choosing not to do so (Table 5). The most common reasons given were that they preferred another provider, believed the CMW was not competent, did not trust her, or, in the case of ANC, did not know she provided said services. Importantly, geographic and social access, cost, marital status of CMW, and lack of CMW clinic/resources did not emerge as important barriers to the respondents' uptake of CMW services. 
Table 3 Odds ratios (OR) and 95\% confidence intervals $(95 \% \mathrm{Cl})$ of $\mathrm{CMW}$-attended births for women in Jhelum and Layyah

\begin{tabular}{|c|c|c|}
\hline & Univariate & Multivariable \\
\hline Variable & OR $(95 \% \mathrm{Cl})$ & OR $(95 \% \mathrm{Cl})$ \\
\hline \multicolumn{3}{|l|}{ District } \\
\hline Layyah & 1.0 & 1.0 \\
\hline Jhelum & $4.27(2.51-7.25)^{*}$ & $6.00(3.26-10.9)^{*}$ \\
\hline \multicolumn{3}{|l|}{ Age } \\
\hline $15-19$ & 1.0 & 1.0 \\
\hline $20-29$ & $0.40(0.15-1.10)$ & $0.50(0.19-1.31)$ \\
\hline $30-39$ & $0.38(0.14-1.03)$ & $0.42(0.15-1.16)$ \\
\hline $40-49$ & $0.34(0.08-1.40)$ & $0.32(0.07-1.42)$ \\
\hline \multicolumn{3}{|l|}{ Education } \\
\hline No Education & 1.0 & 1.0 \\
\hline $1-5$ years schooling & $1.23(0.74-2.03)$ & $0.95(0.53-1.69)$ \\
\hline 6-10 years schooling & $0.81(0.46-1.41)$ & $0.49(0.23-1.06)$ \\
\hline More than 11 years schooling & $0.17(0.03-1.26)$ & $0.09(0.01-1.32)$ \\
\hline \multicolumn{3}{|l|}{ Husband's education } \\
\hline No Education & 1.0 & 1.0 \\
\hline $1-5$ years schooling & $1.25(0.66-2.37)$ & $1.26(0.63-2.56)$ \\
\hline $6-10$ years schooling & $0.68(0.39-1.17)$ & $0.57(0.29-1.09)$ \\
\hline More than 11 years schooling & $0.55(0.23-1.29)$ & $0.86(0.31-2.40)$ \\
\hline \multicolumn{3}{|l|}{ Occupation } \\
\hline Housewife & 1.0 & 1.0 \\
\hline Professional & $0.77(0.15-3.93)$ & $2.37(0.43-13.1)$ \\
\hline Skilled workers & $0.35(0.11-1.12)$ & $0.68(0.20-2.36)$ \\
\hline Unskilled workers $^{\mathrm{a}}$ & $0.57(0.08-4.20)$ & $0.68(0.08-5.67)$ \\
\hline \multicolumn{3}{|l|}{ Husband's occupation } \\
\hline Professional/landowner & 1.0 & 1.0 \\
\hline Skilled worker & $1.43(0.79-2.57)$ & $1.15(0.63-2.10)$ \\
\hline Unskilled labour $^{\mathrm{a}}$ & $1.11(0.60-2.07)$ & $0.83(0.43-1.60)$ \\
\hline Not working & $1.75(0.90-3.41)$ & $1.77(0.88-3.52)$ \\
\hline \multicolumn{3}{|l|}{ Material asset index } \\
\hline First/quartile (poorest) & 1.0 & 1.0 \\
\hline Second quartile & $0.86(0.49-1.51)$ & $0.79(0.42-1.47)$ \\
\hline Third quartile & $0.56(0.30-1.04)$ & $0.54(0.26-1.13)$ \\
\hline Fourth/non-poor & $0.84(0.47-1.50)$ & $1.0(0.47-2.13)$ \\
\hline
\end{tabular}

Respondents' belief that CMWs lack competency is not supported by survey evidence. When comparing respondents' reports of care received, those who had sought CMW services were as likely to receive elements of ANC at rates similar to those who reported care from physicians. These women were as likely to have a blood and urine test, receive two or more tetanus toxoid injections, and take iron supplements as women who received physician care. In fact, CMW clients were significantly more likely to have been weighed $(\mathrm{OR}=1.66, P<0.05)$ and have had discussions about emergency birth-preparedness $(\mathrm{OR}=2.3, P<0.001)$. They were, however, less likely to have had an ultrasound compared to women who sought care from a physician $(\mathrm{OR}=0.16, P<0.001)$.

An analysis of labour and childbirth care provided by the CMWs, as reported by the women, showed that CMWs remained present throughout labour and monitored it with regular vaginal examinations and fetal heart rates $(100 \%$ and $95 \%$, respectively). Over $90 \%$ of them used a safe delivery kit. Use of gloves for vaginal examinations was universal.

\section{Discussion}

The objective of this research was to assess whether the CMW programme, located in the private sector, is expanding coverage of skilled birth attendance, and if any variations in this coverage are associated with demand and cost of CMW care. CMW coverage rates were compared in two distinctly different contexts, the relatively well developed Jhelum and the less developed Layyah, to assess if there were differences in skilled birth attendance between the two districts, and if these variations are reflected in CMW uptake rates. We assumed use of a skilled birth attendant indicated demand for such a provider. The results show that, overall, CMWs have yet to emerge as a significant maternity care provider in rural Punjab. Only $7.9 \%$ of all women who gave birth in the 2 years after deployment of a CMW in their neighbourhood reported a CMW-attended birth. There are, however, large differences in coverage rates between the two districts, with women in Jhelum six times more likely to report a CMW-attended birth. The results also showed that the mean cost of a CMW-attended birth compared favourably with a dai-attended birth. Regardless, the CMWs were continuing to struggle in garnering community trust. The majority of women, when asked why they had not sought care from their neighbourhood CMW, cited a lack of trust in their competency and that they wanted a different provider.

One possible reason for low CMW coverage could be that the programme is relatively new and the CMW cadre relatively unknown; our results support this, as only $47 \%$ of respondents reported they knew of the CMW in their area. At the same time, $47 \%$ is not necessarily a small number and is not reflected in the low use rate of $7.9 \%$, suggesting there may be other reasons for women not using their services besides a lack of awareness of CMW presence.

One of these reasons could be a lack of trust in CMWs competency, as this emerged as the most commonly cited reason for not seeking CMW services. The literature suggests trust and trustworthiness are key factors 
Table 4 Cost of use of community midwife services by district

\begin{tabular}{|c|c|c|c|c|}
\hline \multirow{3}{*}{$\begin{array}{l}\text { Amount of money spent on last } \\
\text { delivery (PKR) }\end{array}$} & \multicolumn{3}{|c|}{ Mean $(95 \% \mathrm{Cl})$ of $\mathrm{PKR}^{\mathrm{a}}$} & \multirow{3}{*}{$P$ value } \\
\hline & \multirow[b]{2}{*}{ Overall } & \multicolumn{2}{|l|}{ District } & \\
\hline & & Jhelum & Layyah & \\
\hline \multicolumn{5}{|l|}{ Type of birth attendant } \\
\hline CMW-attended birth & $2944(2315-3572)$ & $3225(2475-3976)$ & $1760(1000-2520)$ & 0.03 \\
\hline Dai-attended birth & $2254(2059-2448)$ & $3028(2445-3612)$ & $2015(18407-2191)$ & 0.00 \\
\hline Physician-attended birth overall & 13025 (11927-14122) & $14382(1219-15846)$ & $10299(8871-11727)$ & 0.00 \\
\hline Non-physician skilled birth-attendant birth & $3996(3579-4412)$ & $4113(3481-4745)$ & $3834(3355-43132)$ & 0.26 \\
\hline
\end{tabular}

aUS \$1 = PKR 103.

that determine the choice of a provider [21-23]. Lacking trust in providers has been shown to lead to lower patient satisfaction and withdrawal from their care $[24,25]$. While the importance of good interpersonal communication on the part of the provider is acknowledged for building trust, provider competence has been identified as the most important dimension of trust [23]. When patients perceive a provider as incompetent, they lose trust in the provider [26,27]. The present research assessed patients' perception of CMW competence. Although it can be argued that a patient's perception may not be a true reflection of actual provider competence, the literature suggests patient perception of lack of provider competency is itself a powerful determinant of trust [27]. In this case, however, their perception may be reflective of reality as an emerging body of grey literature has identified issues with CMW competencies in Pakistan [12,14].
A second possibility for low CMW coverage is a lack of demand for skilled birth attendance. Assuming use equated demand, a use rate of $86 \%$ suggests a high demand for skilled birth attendance in Jhelum. In contrast, only $52 \%$ of women in Layyah reported skilled birth attendance, with the remaining $48 \%$ using dais. Use of CMWs was much higher in Jhelum versus Layyah (12.4\% vs. $3.4 \%$ of all births). Taking these two findings together suggests the possibility that a greater overall demand for skilled birth attendance in Jhelum provided CMWs greater 'space' to insert themselves into the maternal health marketplace. In contrast, the lower demand for skilled birth attendance in Layyah meant there was less 'space' for the CMWs to enter the market. Ultimately, as indicated by a companion qualitative study, the issue in Layyah was not which type of skilled birth attendant

Table 5 Percent distribution of respondents' cited reasons for not selecting a Community Midwife to provide antenatal care or attend delivery, overall and by district

\begin{tabular}{|c|c|c|c|c|}
\hline \multirow[t]{2}{*}{ Reason cited for not seeking } & \multirow{2}{*}{$\begin{array}{l}\text { Overall } \\
(n=538)\end{array}$} & \multicolumn{2}{|l|}{ District } & \multirow[t]{2}{*}{$P$ value } \\
\hline & & Jhelum $(n=304)$ & Layyah $(n=234)$ & \\
\hline \multicolumn{5}{|l|}{ ANC from CMW } \\
\hline Wanted ANC by other provider & 24.1 & 25.1 & 23.2 & 0.61 \\
\hline CMW is not competent and is not trusted & 22.1 & 24.8 & 19.7 & 0.16 \\
\hline Did not know she provided ANC & 23.4 & 13.9 & 35.9 & 0.00 \\
\hline Not accessible geographically and socially & 10.0 & 4.9 & 17.6 & 0.00 \\
\hline Respondent did not have transport & 0 & 0 & 0 & \\
\hline She has no facilities & 2.8 & 1.3 & 5.2 & 0.10 \\
\hline She is too expensive & 1.4 & 2.3 & 0.4 & 0.07 \\
\hline She is unmarried & 0.9 & 0 & 2.1 & 0.01 \\
\hline \multicolumn{5}{|l|}{ Childbirth attendance from CMW } \\
\hline Wanted birth attended by other provider and CMW is not competent or trusted & 16.1 & 25.0 & 6.0 & 0.00 \\
\hline She is not accessible socially or geographically & 1.8 & 3.0 & 0.4 & 0.03 \\
\hline CMW clinic/house is uncomfortable/does not have necessary facilities & 0.05 & 1.0 & 0 & 0.26 \\
\hline She is too expensive & 1.1 & 1.7 & 0.4 & 0.24 \\
\hline She is unmarried & 0.4 & 0 & 0.9 & 0.19 \\
\hline
\end{tabular}


to use, but whether to use one at all, as dais remained trusted and preferred providers [12].

Another closely related finding supporting the above possibility is that there is no variation in the sociodemographic characteristics of women who reported CMW use. Women, irrespective of levels of education or asset quartiles, are equally likely to report CMW care. Yet Jhelum still had higher proportions of women using their services than did Layyah. One interpretation is that it was the overall high level of development in Jhelum that promoted CMW use. In this context, women's low levels of schooling was less of a determinant of CMW use than the context in which she lived. The results suggest that contextual factors may be as or even more important than individual factors - that typically dominate the maternal health care literature - on skilled birth attendance and inequities. These findings are new in the skilled birth attendant literature, but have been reported previously in family planning literature [28].

It can be postulated that another reason for low use of CMW services is their cost. As discussed above, the CMWs are located in the private sector. Previous qualitative work suggests that CMWs' fees are a deterrent for potential clients [13]. Our survey data, albeit from different districts, shows that the average cost of a CMWattended birth is relatively low, just slightly higher than the traditional birth attendants; this is a new finding from Pakistan. Research from Indonesia found midwives in Banten Province earned, on average in 2007, US \$364 from their private practices [8]. While this amount does not reveal the specific amounts of fees charged for attending a birth, the authors describe it as a reasonably high income [8]. The low fees the Pakistani CMWs charge may, at one level, just be reflective of the fact that CMWs are nascent practitioners, attempting to establish their practices. Charging competitive rates might be a business strategy aimed at attracting clients away from dais. However, a companion qualitative study found that most CMWs were providing care to their relatives, who were charged nominal fees; they charged reasonably high fees, around PKR 6000 (US \$58), for non-relatives [12]. The average was essentially skewed by their relatives' use of their care.

\section{Conclusion}

To summarize, the Pakistani CMWs have yet to emerge as a significant addition to the skilled birth attendant workforce in Pakistan. However, the variation in CMW coverage by development context of a district raises concerns that the CMWs' private sector location might translate into services only for those who can afford to pay while continuing to leave those women most vulnerable to maternal death unserved. This occurred in Indonesia and suggests a need to revisit the concept of private sector midwifery services.
Abbreviations

ANC: Antenatal care; CMW: Community Midwife; MMR: Maternal mortality ratio.

\section{Competing interests}

ZM is funded by the Alberta Innovates Health Solutions through its Alberta Heritage Foundation for Medical Research Population Health Investigator Awards. The authors have no competing interests to declare.

\section{Authors' contributions}

ZM was responsible for conception and design of the study, data collection, analysis, and manuscript development. AL contributed to data analysis and manuscript development. AB collected the data. GJ provided statistical support and contributed to manuscript development. All authors were involved in drafting the article and revising it for critically important intellectual content and all authors approved of the final version to be published.

\section{Acknowledgements}

The authors would like to thank the women and men in our field sites for their generosity of time and for welcoming us into their homes. We also thank the community midwives and the programme personnel, managers, and policymakers of the Pakistan Maternal, Neonatal and Child Health

Programme. In particular, we would like to thank Dr Nisar Cheema, Director General of Health at the time of fieldwork, Dr Zafar Ikram, Provincial

Coordinator MNCH Programme, and Dr Zaheeda Sarwar, Technical Director, Policy and Strategic Planning Unit, Ministry of Health, Government of Pakistan. We also thank our research associates Haleema Masood and Manzhar lqbal.

\section{Funding}

This document is an output from a project funded by the UK Department for International Development (DfID) and the Australian Department of Foreign Affairs and Trade (DFAT) for the benefit of developing countries. The views expressed and information contained in it are not necessarily those of, or endorsed by, DfID, DFAT, or the Maternal and Newborn Health Programme Research and Advocacy Fund (RAF), which can accept no responsibility or liability for such views, for completeness or accuracy of the information, or for any reliance placed on them.

\section{Declaration}

Publication costs for this article were funded by the British Council. This article has been published as part of Health Research Policy and Systems Volume 13 Supplement 1, 2015: Maternal and Newborn Health Research and Advocacy Fund, Pakistan. The full contents of the supplement are available online at http://www.health-policy-systems.com/supplements.

\section{Author details}

${ }^{1}$ School of Public Health, University of Alberta, 3-309 Edmonton Clinic Health Academy, 1140 - 87 Ave, Edmonton, AB T6G 1C9, Canada. ${ }^{2}$ Real Medicine

Foundation Pakistan, Islamabad, Pakistan.

Published: 26 November 2015

\section{References}

1. World Health Organization, UNICEF, UNFPA and The World Bank. Trends in Maternal Mortality: 1990-2010. WHO, UNICEF, UNFPA and the World Bank Estimates. Geneva: WHO, United Nations; 2012. http://www.who.int/ reproductivehealth/publications/monitoring/9789241503631/en/.

2. Hogan MC, Foreman K, Naghavi M, Ahn SY, Wang M, Makela SM, et al. Maternal mortality for 181 countries, 1980-2008. Lancet. 2010;375(9726):1609-23.

3. Government of Pakistan. PC-1 National Maternal, Newborn and Child Health Programme (MNCH). Islamabad: Federal Ministry of Health; 2006.

4. Shankar A, Sebayang S, Guarenti L, Utomo B, Islam M, Fauveau V, et al. The village-based midwife programme in Indonesia. Lancet. 2008;371(9620):1226-9.

5. Webster PC. Indonesia: the midwife and maternal mortality miasma. CMAJ. 2013;185(2):e95-6.

6. Pathmanathan I, Liljestrand J, Martins JM, Rajapaksa LC, Lissner C, de Silva A, et al. Investing in maternal health: learning from Malaysia and Sri Lanka. Washington, DC: The World Bank; 2003. 
7. D'Ambruoso L, Achadi E, Adisasmita A, Izati Y, Makowiecka K, Hussein J. Assessing quality of care provided by Indonesian village midwives with a confidential enquiry. Midwifery. 2009;25(5):528-39.

8. Ensor T, Quayyum Z, Nadjib M, Sucahya P. Level and determinants of incentives for village midwives in Indonesia. Health Policy Plann. 2009;24(1):26-35.

9. Ensor T, Nadjib M, Quayyum Z, Megraini A. Public funding for communitybased skilled delivery care in Indonesia: to what extent are the poor benefiting? Eur J Health Econ. 2008;9(4):385-92.

10. Indonesia S, International M. Indonesia Demographic and Health Survey 2007. Calverton: BPS and Macro International; 2008.

11. Mumtaz Z, Levay A, Bhatti A, Salway S. Good on paper: the gap between programme theory and real-world context in Pakistan's Community Midwife programme. BJOG. 2015;122(2):249-58.

12. Mumtaz Z, Bhatti A, Levay A, Jhangri GS, O'Brien B. Are community midwives addressing the inequities in access to skilled birth attendance in Punjab, Pakistan? Gender, class and social exclusion. Islamabad and Edmonton: Research \& Advocacy Fund Pakistan, the University of Alberta, and Real Medicine Foundation; 2013.

13. Are CMWs accessible in Punjab \& Sindh? A study funded by the Maternal and Newborn Health Programme Research and Advocacy Fund. Pakistan: Arjumand \& Associates; 2012. http://r4d.dfid.gov.uk/pdf/outputs/raf/ SummaryReportPunjab.pdf.

14. Technical Resource Facility. Assessment of the quality of training of community midwives in Pakistan. Islamabad: TTRF and the Government of Pakistan; 2010.

15. Jamal H. Income poverty at district level: An application of small area estimation technique. Karachi: Social Policy and Development Centre; 2007.

16. Pakistan Demographic and Health Survey 2006-07. Islamabad and Calverton, MA: NIPS and Macro International Inc.; 2008. https://dhsprogram. com/pubs/pdf/FR200/FR200.pdf.

17. Aliaga A, Ren R. Optimal sample sizes for two-stage cluster sampling in demographic and health surveys. DHS Working Papers. United States Agency for International Development; 2006

18. Jacoby HG, Mansuri G. Crossing boundaries: gender, caste and schooling in rural Pakistan. Working Paper. Washington, DC: The World Bank; 2011.

19. Mumtaz Z, Salway S, Bhatti A, Shanner L, Zaman S, Laing L, et al. Improving maternal health in Pakistan: towards a deeper understanding of the social determinants of poor women's access to maternal health services. Am J Public Health. 2014;104 Suppl 1:S17-24.

20. Stata: Data Analysis and Statistical Software. http://www.stata.com/.

21. Dinc $L$, Gastmans $C$. Trust and trustworthiness in nursing: an argumentbased literature review. Nurs Inq. 2012;19(3):223-37.

22. Hall MA, Dugan E, Zheng B, Mishra AK. Trust in physicians and medical institutions: what is it, can it be measured, and does it matter? Milbank Q. 2001;79(4):613-39.

23. Sheppard V, Zambrana R, O'Malley A. Providing health care to low-income women: a matter of trust. Fam Pract. 2004;21(5):484-91.

24. Musa D, Schulz R, Harris R, Silverman M, Thomas SB. Trust in the health care system and the use of preventative health services by older black and white adults. Am J Public Health. 2009;99(7):1293-9.

25. Thom DH, Hall MA, Pawlson LG. Measuring patients' trust in physicians when assessing quality of care. Health Aff (Millwood). 2004;23(4):124-32.

26. Tarlier DS. Beyond caring: the moral and ethical bases of responsive nursepatient relationships. Nurs Philos. 2004;5(3):230-41.

27. Hupcey JE, Miller J. Community dwelling adults' perception of interpersonal trust vs trust in health care providers. J Clin Nurs. 2006;15(9):1132-9.

28. Cleland J, Jejeebhoy S. Maternal schooling and fertility: evidence from censuses and surveys. Girls' schooling, women's autonomy, and fertility change in South Asia. New Delhi \& Newbury Park: Sage Publications; 1996.

\section{Submit your next manuscript to BioMed Central and take full advantage of:}

- Convenient online submission

- Thorough peer review

- No space constraints or color figure charges

- Immediate publication on acceptance

- Inclusion in PubMed, CAS, Scopus and Google Scholar

- Research which is freely available for redistribution
C Biomed Central 